\title{
Lipoprotein(a) and its role in inflammation, atherosclerosis and malignancies
}

\author{
Evelyn Orsó $^{1} \cdot$ Gerd Schmitz $^{1}$
}

Published online: 10 February 2017

(C) The Author(s) 2017. This article is available at SpringerLink with Open Access.

\begin{abstract}
Lipoprotein (a) ( $\mathrm{Lp}(\mathrm{a})$ ) is a modified low-density lipoprotein (LDL) particle with an additional specific apolipoprotein (a), covalently attached to apolipoprotein B-100 of LDL by a single thioester bond. Increased plasma $\mathrm{Lp}$ (a) level is a genetically determined, independent, causal risk factor for cardiovascular disease.

The precise quantification of $\mathrm{Lp}(\mathrm{a})$ in plasma is still hampered by mass-sensitive assays, large particle variation, poor standardization and lack of assay comparability.

The physiological functions of $\mathrm{Lp}(\mathrm{a})$ include wound healing, promoting tissue repair and vascular remodeling. Similarly to other lipoproteins, $\mathrm{Lp}(\mathrm{a})$ is also susceptible for oxidative modifications, leading to extensive formation of pro-inflammatory and pro-atherogenic oxidized phospholipids, oxysterols, oxidized lipid-protein adducts in Lp(a) particles, that perpetuate atherosclerotic lesion progression and intima-media thickening through induction of M1macrophages, inflammation, autoimmunity and apoptosis. The oxidation-specific epitopes of modified lipoproteins are major targets of pre-immune, natural IgM antibodies, that may attenuate the pro-inflammatory and pro-atherogenic effects of $\mathrm{Lp}(\mathrm{a})$.

Although the data are still insufficient, recent studies suggest a potential anti-neoplastic role of $\mathrm{Lp}(\mathrm{a})$.
\end{abstract}

This article is part of the special issue " $\mathrm{Lp}(\mathrm{a})$ - the underestimated cardiovascular risk factor"

\footnotetext{
Gerd Schmitz

gerd.schmitz@klinik.uni-regensburg.de

1 Institute for Clinical Chemistry and Laboratory Medicine, University Hospital of Regensburg, Franz-Josef-Strauss-Allee 11, 93053 Regensburg, Germany
}

Keywords Lipoprotein(a) - Pathophysiology · Atherogenesis · Inflammation · Tumor-growth

\section{Introduction}

Lipoprotein(a) (Lp(a)) is one of the most enigmatic lipoprotein particles in humans and its increased plasma concentration is an independent predictor for atherosclerotic cardiovascular disease (CVD) and peripheral arterial disease ([1] and references therein). Mendelian randomization studies have recently provided convincing evidence that $L p(a)$ is a genetically determined causal risk factor for myocardial infarction, atherosclerotic stenosis and aortic valve stenosis (reviewed in [2]). Other disease groups, like heart failure and venous thromboembolism, are under current evaluation [2]. Clinical investigation of Lp(a) is largely hampered by the fact that $\mathrm{Lp}(\mathrm{a})$-hyperlipidemia (Lp(a)-HLP) frequently co-incides with other genetic factors for hyperlipidemia and risk of CVD, such as familial hypercholesterolemia $(\mathrm{FH})$ or apolipoprotein E4-allele [3, 4].

Despite extensive research, the underlying mechanisms by which $\mathrm{Lp}$ (a) mediates atherogenesis and inflammation, and how $\mathrm{Lp}(\mathrm{a})$ contributes to vascular diseases, are still incompletely understood.

\section{Structure and genetics of $\operatorname{Lp}(a)$}

The Lp(a) is largely similar to the low density lipoprotein (LDL) particle, containing one molecule of apolipoprotein B-100 (apoB-100) around a lipid core of cholesteryl esters, triacylglycerols, diverse phospholipids and unesterified cholesterol. In addition, a highly glycosylated, hydrophilic apolipoprotein (a) (apo(a)) is unique for $\mathrm{Lp}(\mathrm{a})$, distinguish- 
ing Lp(a) from LDL (reviewed in [5]). Apo(a) shows a high amino acid sequence homology to the serine protease plasminogen, and consists of a carboxy-terminal, enzymatically inactive, protease-like domain followed by a kringle- $\mathrm{V}$ domain and a variable kringle-IV (K-IV) domain ([5] and references therein). The K-IV domain of apo(a) appears as 10 diverse types (T1-T10) [5]. While T1 and T3-T10 are present as a single copy in one apo(a) molecule, the number of T2 varies between 3 and 43 ([5] and references therein). As a consequence, the different repeats of $\mathrm{K}-\mathrm{IV}_{\mathrm{T} 2}$ in apo(a) account for the high size polymorphism of this apolipoprotein [5]. There is an inverse relationship between the number of $K-I_{\mathrm{T} 2}$ repeats of apo(a) and the level of $\mathrm{Lp}(\mathrm{a})$ in plasma ([1,5] and references therein). The size length of apo(a) largely determines its rate of hepatic synthesis and secretion, and also the mass of circulating $L p(a)$ [6].

Apo(a) is covalently linked to apoB-100 by a single disulfide bond on $\mathrm{K}-\mathrm{IV}_{\mathrm{T}}$, in close proximity to the LDL receptor binding site of apoB-100 (reviewed in [1]). The characteristic 'lysine binding site' (LBS) of apo(a), which is critically important for many cellular effects and atherogenic potential of $\mathrm{Lp}(\mathrm{a})$, is located on $\mathrm{K}-\mathrm{IV}_{\mathrm{T} 10}$ [1].

Apo(a) is encoded by two alleles of the LPA gene (chromosome 6q26), and several genetic LPA-variants have been published, including variations in the K-IV repeats, diverse single nucleotide polymorphisms (SNPs) and other promoter variants in the LPA gene region $[1,2,5]$. The plasma concentrations of $\mathrm{Lp}$ (a) show significant diversity in ethnical groups (e.g. Caucasians have lower plasma Lp(a) levels than African-Americans), and in individuals carrying apo(a) even of the same size polymorphism [7, 8]. Furthermore, elderly individuals (above $75 \mathrm{yrs}$ ) tend to show marginally, but not significantly, elevated plasma levels of $\mathrm{Lp}$ (a) as compared to the general population under $75 \mathrm{yrs}$ [9].

\section{Measurement of $L p(a)$ in plasma}

Although Lp(a) quantification in human plasma (or serum) belongs to standard assays in most clinical laboratories, the precise quantitative analysis of $\mathrm{Lp}(\mathrm{a})$ is still a challenge with many pitfalls: (i) $\mathrm{Lp}$ (a) particles are present in different molecular masses, depending on the differences in isoform size of apo(a), as it varies between 275 and $800 \mathrm{kDa}$ $[10,11]$. Novel commercial Lp(a) assays are now available that are insensitive to the variability in $L p(a)$ mass isoforms [5]. $\mathrm{Lp}(\mathrm{a})$ mass refers to the entire mass of the whole particle, including lipids, proteins and carbohydrates [5, 12]. In addition to the apo(a) isoform mass, however, there is also a large variability in the lipid mass within $\mathrm{Lp}(\mathrm{a})$ particles [12]. Thus, availability of particle-based, mass-insensitive $L p(a)$ assays is of great importance. In a recent paper Guadagno and co-workers presented the validation data of an $\mathrm{Lp}$ (a) particle concentration assay by quantitative lipoprotein immunofixation electrophoresis, showing precision and linearity across a 16 -fold range, which is suitable for use in clinical laboratories [13]. (ii) Most Lp(a) assays are based on immunological methods (e. g. immunonephelometry, immunoturbidimetry, ELISA) using antibodies against apo(a). In contrast to previous immunoassays with antibodies binding to $\mathrm{K}-\mathrm{IV}_{\mathrm{T} 2}$, antibodies in more recent assays should recognize $\mathrm{K}-\mathrm{IV}_{\mathrm{T}}$, since this binding site is more stable than $\mathrm{K}-\mathrm{IV}_{\mathrm{T} 2}$ [10]. (iii) Apo(a) isoforms, selected for previous immunological $\mathrm{Lp}$ (a) assay calibrators, are with small apo(a) sizes, thus leading to a consequent overestimation of $L p(a)$ levels in all clinical samples, in which the apo(a) isoforms are larger than in the calibrator [5]. The approaches for $\mathrm{Lp}(\mathrm{a})$ immunoassay optimization by implementation of international reference reagents have partially solved this analytical problem, and some recently available commercial $\mathrm{Lp}$ (a) assays provide acceptable robustness and analytical precision ([5] and references therein). In addition, the simultaneous quantitation and size characterization of apo(a) by ultra-performance liquid chromatography/mass spectrometry was also reported [14]. (iv) Lp(a) levels, determined by optimized apo(a) isoform dependent assays (see previous point), are delivered in $\mathrm{nmol} / \mathrm{L}$ [5], and this form should be preferred in current studies. However, other Lp(a) assays may report their results in $\mathrm{mg} / \mathrm{L}$. No factor should be used for conversion of $\mathrm{Lp}(\mathrm{a})$ concentrations from $\mathrm{mg} / \mathrm{L}$ to $\mathrm{nmol} / \mathrm{L}$, or vice versa, as this may lead to misinterpretation of data and confusion [5]. (v) Currently, there is no generally accepted patient threshold for elevated plasma $L p(a)$ and the prevalence of Lp(a)-HLP in the general population is not yet defined. In a very recent study an attempt has been made to assess the distribution of plasma $L p(a)$ in a large US-cohort, and the data may influence consensus documents, guidelines and therapeutic cut-offs for $L p(a)$ mediated risk for CVD in the future [15].

\section{Function of $\operatorname{Lp}(\mathbf{a})$}

The physiological role of $L p(a)$ in human is still not fully elucidated, and individuals with extremely low levels of plasma $\mathrm{Lp}$ (a) present no disease or deficiency syndromes [6]. Earlier works agree that $\mathrm{Lp}(\mathrm{a})$ accelerates wound healing and tissue repair, and therefore $\mathrm{Lp}$ (a) provided an evolutionary advantage to humans $[6,16]$. Indeed, $\mathrm{Lp}(\mathrm{a})$ accumulates in endothelial injuries, binds to several components of the vessel wall and the sub-endothelial matrix, stimulates chemotactic activation of monocytes/macrophages, modulates angiogenesis, and all these effects are mediated by apo(a) $[6,16]$. 


\section{Effects of $L p(a)$ on vascular endothelial cells}

In previous years Koschinsky and co-workers have demonstrated in consecutive papers how apo(a) modifies the cellular function of cultured vascular endothelial cells: (i) Apo(a) stimulates migration and proliferation of HUVECs (human umbilical-vein endothelial cells) through a mechanism involving CD51/CD61 (integrin $\alpha_{\mathrm{v}} \beta_{3}$ ), Src and MAP (mitogen-activated protein) kinases, including ERK (extracellular-signal-regulated kinase), p38 and JNK (c-Jun $N$-terminal kinase) [17]. (ii) $\mathrm{Apo}(\mathrm{a})$ induces a RhoA/Rho-kinase signalling, leading to formation of stress fibers, endothelial contraction and vascular permeability [18]. (iii) Apo(a) disrupts VE-cadherin/ $\beta$-catenin complexes via a Src-dependent mechanism, which leads to decreased phosphorylation of $\beta$-catenin, parallel with increased phosphorylation of Akt and glycogen synthase kinase-3 $\beta$. This phosphorylationshift leads to an increased nuclear translocation of $\beta$-catenin and subsequent induction of cyclooxygenase-2 (COX-2) gene expression, thus mediating enhanced prostaglandin $\mathrm{E} 2\left(\mathrm{PGE}_{2}\right)$ formation [19]. (iv) $\mathrm{Apo}(\mathrm{a})$ increases the gene expression of certain adhesion molecules, including CD54 (ICAM-1) and CD62E (E-selectin) by a yet unclear mechanism ([20] and references therein). (v) Apo(a) inhibits pericellular activation of plasminogen by a mechanism involving urokinase-type plasminogen activator (uPA) and CD87 (uPA-receptor), resulting in decreased myoepithelial organization and formation of new vascular tubes ([20] and references therein).

\section{Effects of $\operatorname{Lp}(a)$ on smooth muscle cells}

In addition to endothelial cells, $\mathrm{Lp}$ (a) also influences the function of smooth muscle cells (SMCs) through apo(a): (i) Apo(a) induces a concentration-dependent chemorepulsion of SMCs in migration assays via a mechanism involving CD51/CD61 and RhoA/Rho-kinase, but not transforming growth factor $\beta$ (TGF $\beta$ ) [21]. (ii) $\mathrm{Lp}$ (a) dampens the activity of TGF $\beta$ in SMCs, and the factors contributing to this effect have yet to be identified [16].

\section{Effects of $L p(a)$ on monocytes/macrophages}

It has been demonstrated that $\mathrm{Lp}$ (a) promotes the differentiation of pro-inflammatory, M1-type macrophages, that secrete a set of pro-inflammatory cytokines (e. g. interleukin (IL)-1 $\beta$, IL-6, IL-8, tumor necrosis factor (TNF)$\alpha)$ and chemokines, like 'interferon-gamma-induced protein-10' (IP10, CXCL10) and 'Regulated on Activation, Normal T-cell Expressed and Secreted' (RANTES, CCL5), leading to activation of T-helper-1 (Th1) cells and natural killer (NK) cells [22-25]. The chemokines CXCL10 and
RANTES are accompanied with inhibition of angiogenesis, which may affect function of vasa vasorum [25].

Taken together, the above mentioned cellular effects of $\mathrm{Lp}$ (a) underline its function as potent modulator of tissue remodelling, nevertheless the same mechanisms also contribute to sustained plaque development in atherosclerosis.

\section{Lp(a) and inflammation and atherogenesis}

Similarly to other lipoproteins $\operatorname{Lp}(\mathrm{a})$ is also susceptible to oxidative modifications, leading to formation of pro-inflammatory and pro-atherogenic oxidized phospholipids, oxysterols, oxidized lipid-protein adducts, termed 'oxidationspecific epitopes' (OSEs), produced in response to reactive oxygen species (ROS) $([1,26]$ and references therein). Different OSEs are present on $L p(a)$ as 'danger-associated molecular patterns' (DAMPs) that perpetuate local inflammation, apoptosis and tissue disintegration, and they are recognized by a set of pattern-recognition receptors (PRRs) that trigger innate immunity $[1,26]$. The most important Lp(a)-associated DAMPs, PRRs and their major downstream signalling mechanisms are summarized in Fig. 1.

By using OSE-specific monoclonal antibodies (particularly T15/E06 IgM), recognizing oxidatively modified but not native phospholipids, Witztum, Tsimikas and colleagues found correlations between plasma levels of oxidized phospholipids and plasma $\mathrm{Lp}(\mathrm{a})$, apo(a) size polymorphism, CVD and progression of aortic valve stenosis [1, 26, 27]. Furthermore, by the E06 antibody they were able to block the recognition and uptake of oxidized phospholipids and apoptotic cells by DAMPs, and thus reduce the progression of CVD in atherosclerosis-susceptible mice (reviewed in [1, 26]).

In a recent study Scipione et al. have shown that recombinant apo(a) with 17 subdomains within K-IV induces a dose-dependent increase in expression of IL-8 (mRNA and protein) in macrophage cell lines via CD36 and Tolllike receptor-2 (TLR2)-mediated signalling involving MAP kinases, JNK and ERK [28]. Furthermore, this stimulatory effect was linked to the LBS in K-IV $\mathrm{I}_{\mathrm{T} 10}$ of apo(a), since it was unaffected by trypsin-treatment, but dampened by mutation of the LBS resulting in the loss of oxidized phospholipid on apo(a) [28]. Enzymatic removal of oxidized phospholipid from apo(a) also blunted the IL-8 inducing effect of apo(a), thus verifying the LBS as OSE [28]. Consistent with these results the same group also showed increased monocyte trafficking to the arterial wall in subjects with $\mathrm{Lp}(\mathrm{a})-\mathrm{HLP}$, as compared to probands with normal $\mathrm{Lp}$ (a) levels, using in vivo high resolution imaging techniques [29]. In addition, a parallel ex vivo approach demonstrated the pro-inflammatory activation of monocytes in Lp(a)-HLP 
Fig. 1 Schematic figure depicting major charge-/motif- and opsonin receptors involved in signaling and clearance of oxidized phospholipids, lysophospholipids, oxidized LDL and Lp(a)

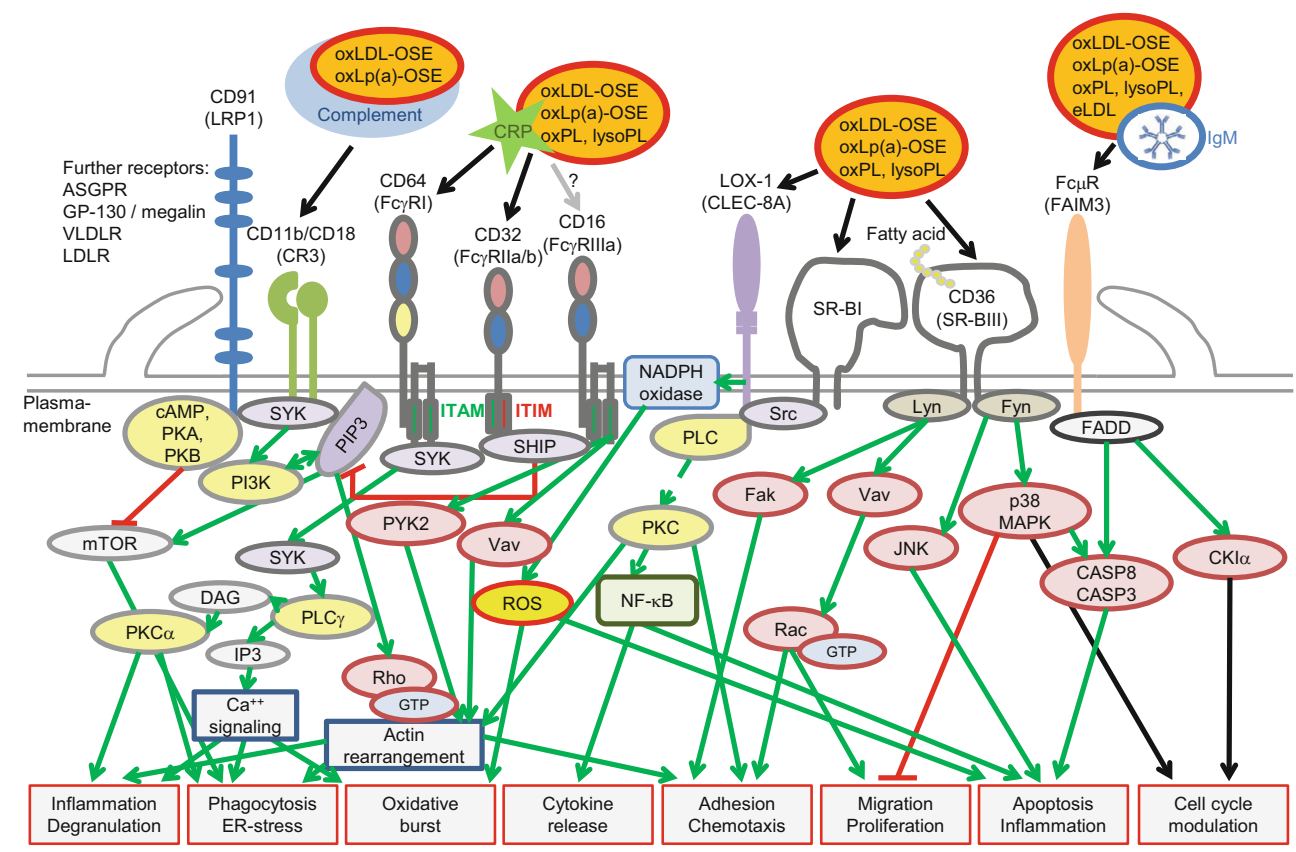

[29]. Furthermore, in vitro experiments revealed that $\mathrm{Lp}(\mathrm{a})$ from $L p(a)-H L P$ patients contained oxidized phospholipids, and this modified $\mathrm{Lp}$ (a) augmented the pro-inflammatory response of monocytes derived from healthy control subjects [29]. The effect was markedly attenuated by inactivating oxidized phospholipids on $\mathrm{Lp}(\mathrm{a})$ or removing them from apo(a) [29]. In this scenario not apo(a) itself, but rather OSEs in apo(a) are responsible for the (patho)physiological function(s) of Lp(a), and the LBS is one of the important OSEs in $\mathrm{Lp}(\mathrm{a})$.

In addition, modified $\mathrm{Lp}$ (a) binds and carries pro-inflammatory molecules such as the monocyte chemoattractant protein-1 (MCP-1/CCL2), a major chemokine inducing and maintaining vascular inflammation, and oxidized phospholipids of modified $\mathrm{Lp}$ (a) were shown to be major determinants for MCP-1 binding [30].

Taken together, $\mathrm{Lp}(\mathrm{a})$ promotes inflammation and atherosclerosis by multiple mechanisms, and OSEs of apo(a) are critically involved in the pathogenesis of $L p(a)$ (Fig. 1).

Association studies have shown that plasma levels of IgM antibodies against OSEs are inversely correlated with CVD (reviewed in [31]), and OSEs are major targets of pre-immune, natural IgM antibodies in humans and mice [32]. Approximately $30 \%$ of all natural IgM antibodies, recognizing diverse OSEs, were found to bind to atherosclerotic lesions and apoptotic cells in a mouse model [32]. Furthermore, genetic deficiency of secreted $\operatorname{IgM}\left(\operatorname{sIg} M^{-/}\right)$in mice dramatically accelerates atherosclerosis on the LDL receptor deficient $\left(L d l r^{-}\right)$, atherosclerosis-susceptible mouse background, parallel with increased plasma IgE levels and perivascular accumulation of mast cells and neutrophils within the plaques [33]. In addition, the OSE-specific T15/E06 IgM blocks the recognition of the oxidized phospholipid POVPC (1-palmitoyl-2-(5oxovaleroyl)-sn-glycero-3-phosphorylcholine) by the scavenger receptor CD36 [34], and the IL-6 secretion, induced by oxPAPC (oxidized 1-palmitoyl-2-arachidonoyl-sn-glycero-3-phosphocholine) in macrophages [35]. The OSEspecific natural NA17 IgM, recognizing a malondialdehyde (MDA) epitope, binds apoptotic cells and promotes their clearance by macrophages [32]. These findings clearly demonstrate the atheroprotective role of natural, OSEspecific IgM antibodies [31].

Autoantibodies against modified LDL were demonstrated in human plasma, and increased levels of these autoantibodies correlated with severe atherosclerosis [36]. Interestingly, elevated levels of IgM autoantibodies against OSE-specific apoB-immune complexes reduced the cardiovascular risk of $\mathrm{Lp}$ (a) in a recent epidemiological study [37]. In previous works Romero et al. reported autoantibodies against MDA-modified Lp(a) in plasma of patients with antiphospholipid syndrome (APS) [38] and systemic lupus erythematosus (SLE) [39], thus linking Lp(a) to autoimmunity. Indeed, similarly to the formation of OSE-specific IgM autoantibodies against modified LDL, autoantibodies against oxidatively modified epitopes of $\mathrm{Lp}(\mathrm{a})$ can also be developed, and these autoantibodies may attenuate the proinflammatory and pro-atherogenic signalling of $\mathrm{Lp}(\mathrm{a})$. 


\section{Lp(a) and malignancies}

It was demonstrated nearly two decades ago that angiostatin, a cancer-mediated proteolytic fragment of plasminogen, is able to inhibit metastasis and neovascularization of tumors [40]. Based on the high grade of homology between plasminogen and apo(a), the potential anti-neoplastic role of $\mathrm{Lp}$ (a) was always postulated, but convincing evidence has not yet been demonstrated ([6] and references therein).

Taking into account that $\mathrm{Lp}$ (a) shows growth-factorlike properties, including stimulation of angiogenesis, one would rather expect that $\mathrm{Lp}$ (a) promotes tumor growth, as malignant cells would likely benefit from neovascularization. Regarding that Lp(a)-HLP is associated with increased amounts of oxidized phospholipids and OSEs, it is tempting to speculate that autoantibodies against oxidized phospholipids develop in Lp(a)-HLP, and these antibodies may antagonize some OSE-associated pro-inflammatory and angiogenic events. Finally, the dampened angiogenic signalling may thus reduce vascularization of tumors.

Previous studies in animal models suggest that the proteolytic break-down fragments of apo(a) are responsible for the anti-angiogenic and anti-neoplastic function of $\mathrm{Lp}(\mathrm{a})$ (reviewed in [41]). In a very recent study $L p(a)$ and vitamin $\mathrm{C}$ were found to impair development of breast cancer in a mouse model, transgenic for human $\mathrm{Lp}$ (a) and deficient in endogenous vitamin C production [42].

Despite promising in vivo and in vitro results epidemiological studies have failed to clearly link $\mathrm{Lp}(\mathrm{a})$ with tumor protection so far. In a recent work Sawabe and colleagues reported a link between low $\mathrm{Lp}$ (a) levels and all-cause and cancer death [43]. The same group found Lp(a)-HLP as a significant risk factor for any origins of cancer [44]. Furthermore, increased $\mathrm{Lp}$ (a) levels in plasma is commonly reported in tumor patients in comparison to controls, irrespective of source of the tumor $[6,41,45,46]$.

Taken together, the current knowledge about the antineoplastic function is insufficient and further investigations are required to clarify this important question.

\section{Conclusion}

In recent years several important consecutive data have been presented showing cellular and molecular mechanisms of $\mathrm{Lp}$ (a) action. Convincing evidence has been presented that the pro-inflammatory and pro-atherosclerotic effects of $\mathrm{Lp}$ (a) are largely attributed to different OSEs present in Lp(a) particles.

Different OSEs are major targets of pre-immune, natural IgM antibodies, and autoantibodies against oxidized phospholipids may develop in Lp(a)-HLP, thus antagonizing the detrimental effects of $L p(a)$.
The anti-neoplastic effect of $L p(a)$ is not convincingly demonstrated, and further investigations are necessary to clarify this question.

Despite emerging data from clinical and experimental studies our current knowledge about the impact of $L p(a)$ HLP in diverse pathologies is still rudimentary. For further studies establishment of novel biomarkers and particlebased, mass-insensitive assays for quantification of $L p(a)$ are essentially required.

Acknowledgements This work was supported by the $7^{\text {th }}$ Framework Program of the European Community (FP7/2007-2013) under grant agreement $N^{\circ} 202272$, IP-Project LipidomicNet (Lipid droplets as dynamic organelles of fat deposition and release: translational research towards human disease).

Conflict of interest E. Orsó and G. Schmitz declare that they have no competing interests.

Open Access This article is distributed under the terms of the Creative Commons Attribution 4.0 International License (http:// creativecommons.org/licenses/by/4.0/), which permits unrestricted use, distribution, and reproduction in any medium, provided you give appropriate credit to the original author(s) and the source, provide a link to the Creative Commons license, and indicate if changes were made.

\section{References}

1. Leibundgut G, Scipione C, Yin H, Schneider M, Boffa MB, Green S, Yang X, Dennis E, Witztum JL, Koschinsky ML, Tsimikas S (2013) Determinants of binding of oxidized phospholipids on apolipoprotein (a) and lipoprotein (a). J Lipid Res 54:2815-2830. doi:10.1194/jlr.M040733

2. Nordestgaard BG, Langsted A (2016) Lipoprotein (a) as a cause of cardiovascular disease: insigths from epidemiology, genetics, and biology. J Lipid Res 57:1953-1975. doi:10.1194/jlr.R071233

3. Orsó E, Ahrens N, Kilalić D, Schmitz G (2009) Familial hypercholesterolemia and lipoprotein(a) hyperlipidemia as independent and combined cardiovascular risk factors. Atheroscler Suppl 10:74-78. doi:10.1016/S1567-5688(09)71816-1

4. Schmitz G, Orsó E (2015) Lipoprotein(a) hyperlipidemia as cardiovascular risk factor: pathophysiological aspects. Clin Res Cardiol Suppl 10:21-25. doi:10.1007/s11789-015-0074-0

5. Marcovina SM, Albers JJ (2016) Lipoprotein (a) measurements for clinical application. J Lipid Res 57:526-537. doi:10.1194/jlr. R061648

6. Lippi G, Guidi G (2000) Lipoprotein(a): from ancestral benefit to modern pathogen? Q J Med 93:75-84

7. Rubin J, Kim HJ, Pearson TA, Holleran S, Berglund L, Ramakrishnan R (2008) The apolipoprotein(a) gene: linkage disequilibria at three loci differs in African Americans and Caucasians. Atherosclerosis 201:138-147. doi:10.1016/j.atherosclerosis.2008.01.002

8. Chretien JP, Coresh J, Berthier-Schaad Y, Kao WH, Fink NE, Klag MJ, Marcovina SM, Giaculli F, Smith MW (2006) Three single-nucleotide polymorphisms in LPA account for most of the increase in lipoprotein(a) level elevation in African Americans compared with European Americans. J Med Genet 43:917-923. doi:10.1136/jmg. 2006.042119

9. Lippi G, Targher G, Salvagno GL, Montagnana M, Franchini M, Guidi GC (2010) Lipoprotein(a) and ageing. Clin Lab 56:463-466 
10. Scanu AM, Edelstein C (1997) Learning about the structure and biology of human lipoprotein [a] through dissection by enzymes of the elastase family: facts and speculations. J Lipid Res 38:2193-2206

11. Durrington PN, Schofield JD, Siahmansur T, Soran H (2014) Lipoprotein (a): gene genie. Curr Opin Lipidol 25:289-296. doi:10. 1097/MOL.0000000000000096

12. McConnell JP, Guadagno PA, Dayspring TD, Hoefner DM, Thiselton DL, Warnich GL, Harris WS (2014) Lipoprotein(a) mass: a massively misunderstood metric. J Clin Lipidol 8:550-553. doi:10. 1016/j.jacl.2014.08.003

13. Guadagno PA, Summers Bellin EG, Harris WS, Dayspring TD, Hoefner DM, Thiselton DL, Stanovick B, Warnick GR, McConnell JP (2015) Validation of a lipoprotein(a) particle concentration assay by quantitative lipoprotein immunofixation electrophoresis. Clin Chim Acta 439:219-224. doi:10.1016/j.cca.2014.10.013

14. Lassman ME, McLaughlin TM, Zhou H, Pan Y, Marcovina SM, Laterza O, Roddy TP (2014) Simultaneous quantitation and size characterization of apolipoprotein(a) by ultra-performance liquid chromatography/mass spectrometry. Rapid Commun Mass Spectrom 28:1101-1106. doi: $10.1002 / \mathrm{rcm} .6883$

15. Varvel S, McConnell JP, Tsimikas S (2016) Prevalence of elevated $\mathrm{Lp}$ (a) mass levels and patient thresholds in 532359 patients in the Unites States. Arterioscler Thromb Vasc Biol 36:2239-2245. doi:10.1161/ATVBAHA.116.308011

16. Leischik R, Dworrak B (2006) Lipoprotein(a): Bedeutung für das fibrinolytische System und thromboembolische Komplikationen. Herz 31:144-152. doi:10.1007/s00059-006-2714-0

17. Liu L, Craig AW, Meldrum HD, Marcovina SM, Elliott BE, Koschinsky ML (2009) Apolipoprotein(a) stimulates vascular endothelial cell growth and migration and signals through integrin $\alpha \mathrm{V} \beta 3$. Biochem J 418:325-336. doi:10.1042/BJ20080744

18. Cho T, Jung Y, Koschinsky ML (2008) Apolipoprotein(a), through its strong lysine-binding site in KIV10, mediates increased endothelial cell contraction and permeability via a Rho/Rho kinase/MYPT1-dependent pathway. J Biol Chem 283:30503-30512. doi:10.1074/jbc.M802648200

19. Cho T, Romagnuolo R, Scipione C, Boffa MB, Koschinsky ML (2013) Apolipoprotein(a) stimulates nuclear translocation of $\beta$-catenin: a novel pathogenis mechanism for lipoprotein(a). Mol Biol Cell 24:210-221. doi:10.1091/mbc.E12-08-0637

20. Liu L, Boffa MB, Koschinsky ML (2013) Apolipoprotein(a) inhibits in votro tube formation in endothelial cells: identification of roles for kringle $\mathrm{V}$ and the plasminogen activation system. PLOS ONE 8:e52287. doi:10.1371/journal.pone.0052287

21. Riches K, Franklin L, Maqbool A, Peckham M, Adams M, Bond J, Warburton P, Feric NT, Koschinsky ML, O'Regan DJ, Ball SG, Turner NA, Porter KE (2013) Apolipoprotein(a) acts as a chemorepellent to human vascular smooth muscle cells via integrin $\alpha \mathrm{V} \beta 3$ and RhoA/ROCK-mediated mechanisms. Int J Biochem Cell Biol 45:1776-1783. doi:10.1016/j.biocel.2013.05.021

22. Mantovani A, Biswas SK, Galdiero MR, Sica A, Locati M (2013) Macrophage plasticity and polarization in tissue repair and remodeling. J Pathol 229:176-185. doi:10.1002/path.4133

23. Buechler C, Ullrich H, Ritter M, Porsch-Oezcueruemez M, Lackner KJ, Barlage S, Friedrich SO, Kostner GM, Schmitz G (2001) Lipoprotein(a) up-regulates the expression of the plasminogen activator inhibitor-2 in human monocytes. Blood 97:981-986

24. Buechler C, Ullrich H, Aslanidis C, Bared SM, Lingenhel A, Ritter M, Schmitz G (2003) Lipoprotein(a) down-regulates lisosomal acid lipase and induces interleukin- 6 in human blood monocytes. Biochim Biophys Acta 1642:25-31

25. Pickert G, Lim HY, Weigert A, Häussler A, Myrczek T, Waldner M, Labocha S, Ferreirós N, Geisslinger G, Lötsch J, Becker C, Brüne B, Tegeder I (2013) Inhibition of GTP cyclohydrolase attenuates tumor growth by reducing angiogenesis and M2-like polarization of tumor associated macrophages. Int J Cancer 132:591-604. doi:10. 1002/ijc. 27706

26. Leibundgut G, Witztum JL, Tsimikas S (2013) Oxidation-specific epitopes and immunological responses: translational biotheranostic implications for atherogenesis. Curr Opin Pharmacol 13:166-179. doi:10.1016/j.coph.2013.02.005

27. Capoulade R, Chan KL, Yeang C, Mathieu P, Bossé Y, Dumesnil JG, Tam JW, Teo KK, Mahmut A, Yang X, Witztum JL, Arsenault BJ, Després JP, Pibarot P, Tsimikas S (2015) Oxidized phospholipids, lipoprotein(a), and progression of calcific aortic valve stenosis. J Am Coll Cardiol 66:1236-1246. doi:10.1016/j.jacc.2015.07. 020

28. Scipione CA, Sayegh SE, Romagnuolo R, Tsimikas S, Marcovina SM, Boffa MB, Koschinsky ML (2015) Mechanistic insights into Lp(a)-induce IL-8 expression: a role for oxidized phospholipid modification of apo(a). J Lipid Res 56:2273-2285. doi:10.1194/jlr. M060210

29. van der Valk FM, Bekkering S, Kroon J, Yeang C, Van den Bossche J, van Buul JD, Ravandi A, Nederveen AJ, Verberne HJ, Scipione C, Nieuwdorp M, Joosten LA, Netea MG, Koschinsky ML, Witztum JL, Tsimikas S, Riksen NP, Stroes ES (2016) Oxidized phospholipids on lipoprotein(a) elicit arterial wall inflammation and an inflammatory monocyte response in humans. Circulation 134:611-624. doi:10.1161/CIRCULATIONAHA.116.020838

30. Wiesner P, Tafelmeier M, Chittka D, Choi SH, Zhang L, Byun YS, Almazan F, Yang X, Iqbal N, Chowdhury P, Maisel A, Witztum JL, Handel TM, Tsimikas S, Miller YI (2013) MCP-1 binds to oxidized LDL and is carried by lipoprotein(a) in human plasma. J Lipid Res 54:1877-1883. doi:10.1194/jlr.M036343

31. Tsiantoulas D, Diehl CJ, Witztum JL, Binder CJ (2014) B cells and humoral immunity in atherosclerosis. Circ Res 114:1743-1756. doi:10.1161/circresaha.113.301145

32. Chou MY, Fogelstrand L, Hartvigsen K, Hansen LF, Woelkers D, Shaw PX, Choi J, Perkmann T, Bäckhed F, Miller YI, Hörkkö S, Corr M, Witztum JL, Binder CJ (2009) Oxidation-specific epitopes are dominant targets of innate natural antibodies in mice and humans. J Clin Invest 119:1335-1349. doi:10.1172/jci36800

33. Tsiantoulas D, Bot I, Ozsvar Kozma M, Goederle L, Perkmann T, Hartvigsen K, Conrad DH, Kuiper J, Mallat Z, Binder CJ (2016) Increased plasma IgE accelerate atherosclerosis in secreted IgM deficiency. Circ Res 120(1):78-84. doi:10.1161/circresaha.116.309606

34. Boullier A, Gillotte KL, Hörkkö S, Green SR, Friedman P, Dennis EA, Witztum JL, Steinberg D, Quehenberger O (2000) The binding of oxidized low density lipoprotein to mouse CD36 is mediated in part by oxidized phospholipids that are associated with both the lipid and protein moieties of the lipoprotein. J Biol Chem 275:9163-9169

35. Imai Y, Kuba K, Neely GG, Yaghubian-Malhami R, Perkmann T, van Loo G, Ermolaeva M, Veldhuizen R, Leung YH, Wang H, Liu H, Sun Y, Pasparakis M, Kopf M, Mech C, Bavari S, Peiris JS, Slutsky AS, Akira S, Hultqvist M, Holmdahl R, Nicholls J, Jiang C, Binder CJ, Penninger JM (2008) Identification of oxidative stress and Toll-like receptor 4 signaling as a key pathway of acute lung injury. Cell 133:235-249. doi:10.1016/j.cell.2008.02.043

36. Tsimikas S, Brilakis ES, Lennon RJ, Miller ER, Witztum JL, McConnell JP, Kornman KS, Berger PB (2007) Relationship of IgG and $\operatorname{IgM}$ autoantibodies to oxidized low density lipoprotein with coronary artery disease and cardiovascular events. J Lipid Res 48:425-433. doi:10.1194/jlr.m600361-j1r200

37. Ravandi A, Boekholdt SM, Mallat Z, Talmud PJ, Kastelein JJ, Wareham NJ, Miller ER, Benessiano J, Tedgui A, Witztum JL, Khaw KT, Tsimikas S (2011) Relationship of IgG and IgM autoantibodies and immune complexes to oxidized LDL with markers of oxidation and inflammation and cardiovascular events: results from the EPIC-Norfolk study. J Lipid Res 52:1829-1836. doi:10.1194/ jlr.m015776 
38. Romero FI, Atsumi T, Tinahones FJ, Gómez-Zumaquero JM, Amengual O, Khamashta MA, Hughes GR (1999) Autoantibodies against malondialdehyde-modified lipoprotein(a) in antiphospholipid syndrome. Arthritis Rheum 42(12):2606-2611. doi:10.1002/ 1529-0131(199912)42:12<2606::aid-anr14>3.0.co;2-x

39. Romero FI, Khamashta MA, Hughes GR (2000) Lipoprotein(a) oxidation and autoantibodies: a new path in atherothrombosis. Lupus 9:206-209

40. O'Reilly MS (1997) Angiostatin: an endogenous inhibitor of angiogenesis and of tumor growth. EXS 79:273-294

41. Lippi G, Franchini M, Salvagno GL, Guidi GC (2007) Lipoprotein[a] and cancer: anti-neoplastic effect besides its cardiovascular potency. Cancer Treat Rev 33:427-436. doi:10.1016/j.ctrv.2007.02. 006

42. Cha J, Roomi MW, Kalinovsky T, Niedzwiecki A, Rath M (2016) Lipoprotein(a) and vitamin C impair development of breast cancer tumors in Lp(a)+; Gulo-/- mice. Int J Oncol 49:895-902. doi:10. 3892/ijo.2016.3597

43. Sawabe M, Tanaka N, Mieno MN, Ishikawa S, Kayaba K, Nakahara K, Matsushita S, JMS Cohort Study Group (2012) Low lipoprotein(a) concentration is associated with cancer and all-cause deaths: a population-based cohort study (the JMS cohort study). PLOS ONE 7:e31954. doi:10.1371/journal.pone.0031954

44. Mieno MN, Sawabe M, Tanaka N, Nakahara K, Hamamatsu A, Chida K, Sakurai U, Arai T, Harada K, Mori S, Inamatsu T, Ozawa T, Honma N, Aida J, Takubo K, Matsushita S (2014) Significant association between hypolipoproteinemia(a) and lifetime risk of cancer: an autopsy study from a community-based Geriatric Hospital. Cancer Epidemiol 38:550-555. doi:10.1016/j.canep.2014.07.013

45. Yang HH, Chen XF, Hu W, Lv DQ, Ding WJ, Tang LJ, Jiang JJ, Ye MH (2009) Lipoprotein(a) level and its association with tumor stage in male patients with primary lung cancer. Clin Chem Lab Med 47:452-457. doi:10.1515/cclm.2009.094

46. Li G, Da M, Zhang W, Wu H, Ye J, Chen J, Ma L, Gu N, Wu Y, Song X (2016) Alteration of serum lipid profile and its prognostic value in head and neck squamous cell carcinoma. J Oral Pathol Med 45:167-172. doi:10.1111/jop.12344 